\title{
EDUCAÇÃO AMBIENTAL NO ENSINO FORMAL: NARRATIVAS DE PROFESSORES SOBRE SUAS EXPERIÊNCIAS E PERSPECTIVAS'
}

\author{
Regina Mendes* \\ Arnaldo Vaz *
}

RESUMO: Este trabalho apresenta dados da dissertação de mestrado O Papel da Escola na Educação Ambiental: experiências e perspectivas de professores, na qual investigamos o que os professores consideram relevante para a abordagem de temas de Educação Ambiental (EA) na escola. Para tanto, levantamos e classificamos experiências e perspectivas de professores com relação à EA no ensino formal. No presente artigo, enfatizamos: (i) a estratégia metodológica que utilizamos nesse levantamento e (ii) a maneira como os saberes docentes permeiam as experiências e as perspectivas desses professores. Esta pesquisa, através da composição de um repertório de conhecimentos sobre educação ambiental em espaços formais de ensino, sinaliza a importância dos saberes docentes para a formação desses profissionais e para a pesquisa em educação ambiental.

Palavras-chave: Saberes Docentes; Narrativas; Grupo Focal.

\section{ENVIRONMENTAL EDUCATION WITHIN SCHOOLS: \\ REVEALING TEACHERS' EXPERIENCES AND PERSPECTIVES}

ABSTRACT: This paper is based on the monographic work "O Papel da Escola na Educação Ambiental: experiências e perspectivas de professores" ("The role of school on Environmental Education: teachers' experiences and perspectives") in which we investigate how teachers have been contributing to the implementation of environmental education practices in basic schools, conducted through the analysis of the teachers' experiences and perspectives on formal environmental education. In this article, we have emphasized: (i) the methodological design used and (ii) the way the teachers' knowledge interweave with their experiences and perspectives in this area. As consequence, we would like to point out the importance of this knowledge for teachers and for researches in environmental education - through the composition of a repertory of knowledge on environmental education within formal schooling.

Keywords: Teachers' Knowledge; Narrative Knowledge; Group Focus Technique.

\footnotetext{
* Doutora em Educação pela Universidade Federal de Minas Gerais (UFMG); Pesquisadora na área de Educação Ambiental e Formação de Professores e Professora Assistente de Prática de Ensino e Estágio Supervisionado na Universidade Estadual do Rio de Janeiro (UERJ). E-mail. remendes@biologiaufrij.br

** Doutor em Educação pela University of Surrey, Inglaterra; Professor no Colégio Técnico e no Programa de Pós-Graduação em Educação da Universidade Federal de Minas Gerais (UFMG). E-mail: arnaldovaz@ufmg.br
} 


\section{A relação entre os professores e a prática escolar da Educação Ambiental}

Embora não seja uma disciplina escolar nem responsabilidade da escola básica, a Educação Ambiental (EA) nela pode ser trabalhada por meio de iniciativas pessoais e de grupos multidisciplinares de professores. No Brasil, há registros sobre iniciativas isoladas de inserção de temas ambientais no ensino formal a partir da década de 1950. Na sua maioria, eram atividades realizadas por professores do ensino básico e do ensino superior, que saíam das salas de aula com seus alunos para observar e estudar o ambiente que circundava a escola, o bairro, a cidade. Saídas que alguns chamavam de "estudos do meio" ou "trabalho de campo".

Em 1988, pela Constituição Federal (BRASIL, 1988), a EA passou a ser obrigatória em todos os níveis de ensino, sem ser tratada como disciplina isolada. Os subsídios para os professores implementarem essa determinação estão nos Parâmetros Curriculares Nacionais (PCN), os quais apresentam ao professor diretrizes educacionais nacionais de reflexão sobre o trabalho com os alunos e, também, diretrizes para a ação. Nos PCN, o tema Meio Ambiente é abordado de forma transversal, sugerindo que a EA seja trabalhada em todos os ciclos do ensino fundamental, por todas as áreas do conhecimento (BRASIL, 1997b).

Apesar dessas iniciativas, a EA tem sido introduzida nos ambientes formais de ensino sem uma maneira sistematizada de registro. Essa sistematização, ao nosso ver, poderia contribuir para a formação de um repertório de conhecimentos (GAUTHIER et al., 1998) sobre a EA Formal e, consequentemente, para o crescimento da pesquisa nessa área.

Os documentos oficiais dão indícios da desatenção dos órgãos públicos em relação ao que já se faz. Sente-se, por exemplo, que são ignorados tanto a riqueza das práticas de EA em curso quanto o potencial criativo dos professores no tratamento da EA em sala de aula. Percebendo tal situação, decidimos investigar o processo de inserção da EA na escola e fazê-lo com base nas perspectivas dos próprios professores. Por isso, nossa investigação envolveu docentes que trabalham a EA na escola ou que se interessam pelo tema.

Estávamos especialmente interessados nas trocas de experiências que, usualmente, ocorrem quando professores - que têm interesses comuns - se reúnem. O compartilhamento e a discussão dessas experiências entre pares contribuem para a difusão mais efetiva da EA do 
que aquela promovida pelas iniciativas oficiais: documentos e cursos. $\mathrm{O}$ professor, por ser um profissional que vive situações conflituosas, complexas e instáveis, possui um saber particular e próprio da sua profissão (Cf. SCHÖN, 1983; NÓVOA, 1992; TARDIF, 2008; TARDIF; LESSARD, 2008). Portanto, a construção da prática ambiental dos professores junto a seus alunos depende desse saber e com ele se enriquece. Assim, além de contribuírem para a difusão da prática de EA nas escolas, as trocas de ideias permitem ao professor explicitar aos seus colegas um saber que ele mesmo desenvolveu e do qual pode resultar o estabelecimento de uma identidade profissional docente desses professores.

Para justificar a escolha que fizemos de estratégia metodológica, apresentamos a seguir as ideias relativas a saberes docentes que a sustentam.

\section{Os saberes dos professores}

A valorização do professor, como profissional que possui saberes específicos que auxiliam no exercício de seu ofício, ocorre na década de 1980, quando a atividade docente passa a ser considerada como fator influente nos processos de ensino-aprendizagem (GAUTHIER et al., 1998, p. 60). Desde então, tem-se reivindicado que ele passe a ser visto como um profissional dotado de saberes que fundamentam sua profissão, assim como ocorre com o profissional de outras categorias (médicos, juízes, artistas, etc.). Esses saberes se formam, por um lado, partindo das condições concretas, nas quais o trabalho dos docentes se realiza e, por outro lado, levando em conta sua personalidade e experiência profissional (TARDIF, 2008, p.16).

Outra reivindicação que surge dentro desse contexto é a de que se crie uma base de conhecimentos para o ensino, que deveria estruturar a formação de professores e informar diretamente a prática dos mesmos (SHULMAN, 1987, p. 4).

Discutindo, portanto, a formação dessa base de conhecimentos para o ensino, Shulman procura enfatizar, em seu trabalho, a necessidade de ela considerar - para além das habilidades básicas — o conhecimento de conteúdo e as habilidades pedagógicas gerais. Para esse autor, uma 
nova visão do ensino deve levar em conta que um professor sabe algo que outros — na maior parte das vezes, os alunos — não sabem. Ele pode transformar entendimento, habilidades de performance ou valores e atitudes desejadas em representações e ações pedagógicas. Dessa forma, por meio da fala, da demonstração, da ordenação, etc., pode representar ideias a partir das quais aquele que não sabe passa a saber, o que não entende passa a compreender e discernir, e o que era incapaz se torna hábil e capacitado.

Shulman nomeia essa outra categoria de conhecimentos para o ensino de pedagogical content knowledge ou conhecimento pedagógico de conteúdo. De maneira prática, poderíamos dizer que esse conhecimento trata das formas de representar e explicar a matéria, como ideias, analogias, ilustrações, exemplos, explicações e demonstrações, que tornam essa matéria compreensível aos alunos (SHULMAN, 1986, p. 9).

Para a área da Educação Ambiental, é importante não só destacar esse tipo de conhecimento desenvolvido pelo professor, como também aprofundar suas conexões com a difusão de temas e conceitos relativos à área, porque o trabalho escolar com a EA tem buscado o desenvolvimento de valores, atitudes e comportamentos humanos que considerem a relação entre sociedade e natureza. Pela complexidade de abordagem, a EA encontra interface na habilidade dos professores em desenvolverem meios de ensinar, atividade por si só complexa e sujeita a situações inesperadas.

Para Shulman (1986, p. 10), os saberes dos professores sobre o ensino podem ser comunicados de três diferentes formas: por meio do enunciado de proposições; por meio da narração de casos ou episódios de ensino; ou por meio da vivência de dilemas teóricos, práticos ou morais. Se o professor escolhe passar determinado conhecimento usando proposições, casos ou dilemas vividos em sua prática, o que vai influenciar o modo como o conhecimento será transmitido é, primeiro, o momento do compartilhamento daquela experiência e, segundo, o objetivo de fazêlo. Observamos que existe uma tendência de o professor se comunicar mais através de exemplos do que de proposições. A referência a casos e exemplos, inclusive, é mais apreciada por seus colegas de trabalho. Contudo, a comunicação por narrativa não é considerada na área acadêmica, que valoriza mais a linguagem proposicional, à qual associa maior domínio do conhecimento que se quer transmitir. A desvalorização 
das narrativas docentes contribui para disseminar a visão de que o professor não é capaz de produzir conhecimento, apenas de aplicá-lo. Da mesma forma, muitos pesquisadores não se interessam em entender a linguagem do professor como outra maneira possível de comunicação e de produção de conhecimentos, evitando, assim, uma aproximação profícua entre o seu universo e o universo da prática docente. Em trabalho coletivo anterior (VAZ; MENDES; MAUÉS, 2001), desenvolvemos o argumento de que é possível lidar com essa linguagem do professor e com os saberes que permeiam sua prática se aprendermos a ouvir suas narrativas.

Narrativas de episódios sobre práticas de educação ambiental na escola realizadas por professores são a matéria-prima de nossa investigação. Por isso, passamos agora ao conceito de narrativa.

\section{A narrativa como princípio organizador de experiências}

Como argumentam Connelly e Clandinin (1995), o homem é essencialmente um contador de histórias, das quais extraímos sentido. As narrativas têm sua origem na narração de histórias e são "muito provavelmente uma das primeiras e mais naturais formas pela qual organizamos nossa experiência e nosso conhecimento" (BRUNER, 2001, p. 119).

Estruturalmente, as narrativas se compõem de uma sequência singular de eventos, mentais ou factuais, que envolvem seres humanos. Ricoeur (1981), citado por Bruner (1997), resume como funciona a estrutura narrativa:

Uma história descreve uma seqüência de ações e experiências de um determinado número de personagens, sejam reais ou imaginários. Esses personagens são representados em situações que mudam (...) às quais eles reagem. Essas mudanças, por sua vez, revelam aspectos ocultos das situações e dos personagens, dando lugar a uma nova condição que pede reflexão ou ação, ou ambos. A resposta a esta condição leva a história à sua conclusão. (BRUNER, 1997, p. 46).

A narrativa é, portanto, uma história bem-contada. E, desse modo, devemos levar em conta que seu significado é negociado, ou seja, cada interlocutor tem a liberdade de entender a história como lhe 
aprouver. Entretanto, ela não está isenta de intenção, na medida em que uma das características da narrativa são seus estados intencionais. Segundo Bruner (2001, p. 131), “o que as pessoas fazem nas narrativas nunca é por acaso, nem estritamente determinado por causa e efeito; o que elas fazem é motivado por crenças, desejos, teorias, valores e outros 'estados intencionais'. As ações narrativas implicam estados intencionais”.

Para os pesquisadores da área de educação, essa é uma observação relevante porque o relato narrativo da prática docente pode vir a mostrar os estados intencionais que levam determinado professor a realizar determinadas atividades com seus alunos, revelando suas perspectivas sobre a atividade e sobre suas consequências pedagógicas. E, dentro do contexto de comunicação entre os pares, a narrativa também mostra qual o objetivo do professor ao relatar aquela experiência naquele momento, para aquele grupo de colegas de profissão.

\section{Uma metodologia para nossa necessidade}

Investigamos a inserção de temas de educação ambiental no ensino formal, pois queríamos não somente entender como os professores lidam com essa prática educativa, como, igualmente, saber que reflexão fazem a respeito. Nosso interesse por suas perspectivas vai além da preocupação em identificar suas atitudes e opiniões, que são apenas reflexo das perspectivas de um indivíduo. Gimeno (1988), citado por Pacheco (1995), traz a seguinte definição do termo:

As perspectivas não são simples atitudes perante os fatos, têm essa componente ativa que se projeta na ação. Representam uma matriz de pressupostos que dão sentido ao mundo, não sendo, contudo, um simples reflexo da realidade, mas sim algo construído no decurso da interação com outros, com essa realidade, na experiência. Em suma, não podem ver-se à margem da sua cultura, em geral, e da sua cultura profissional, em particular, já que expressam precisamente uma forma de estruturação dessa cultura vivenciada. (PACHECO, 1995, p. 54)

Da mesma forma, trabalhar com experiências é mais do que trabalhar com hipóteses ou planejamentos. Ao contar sua experiência, o pesquisado gera maior interesse do grupo ao qual está se dirigindo e acaba 
provocando uma troca dinâmica, que se caracteriza como principal componente de um debate. Ao longo desse processo, vai elaborando seu discurso e tomando consciência de seus saberes.

Em síntese, perspectivas e experiências de professores foram nossas categorias iniciais de análise. Apostamos que poderíamos sempre identificar, nas narrativas, episódios em que essas categorias estivessem presentes. Pusemo-nos, então, a desenvolver um delineamento metodológico que permitisse aos professores envolvidos narrar episódios ricos de significados. Percebemos que, se promovêssemos debates entre eles, atingiríamos nosso objetivo. Numa dinâmica desse tipo, caberia a nós acompanhar o processo coletivo de formação de opinião, extraindo dele temas, ideias e impressões que colaboram para a construção de um repertório de conhecimentos sobre a educação ambiental formal.

O delineamento final da metodologia se baseia na técnica de Grupo Focal, que merece uma descrição à parte.

\section{A técnica do Grupo Focal}

A técnica do Grupo Focal foi criada como uma ferramenta para se estudar temas num contexto coletivo, baseando-se nas impressões de um conjunto de indivíduos. $\mathrm{Na}$ pesquisa qualitativa, essa técnica funciona basicamente como uma entrevista em grupo. O que se pode destacar como peculiaridade desse método é a interação que acontece entre um conjunto de pessoas ao serem convidadas a debater um tema levantado pelo pesquisador, que, normalmente, tem o papel de moderador da discussão. Os dados utilizados na análise dessa interação são as transcrições das discussões do grupo. A ênfase na busca de ideias trazidas coletivamente, e não individualmente, é o que identificou nossa pesquisa com essa metodologia.

A metodologia de Grupo Focal teve origem no campo da Sociologia, na década de 1940, com os trabalhos de Merton e Kendall sobre a persuasão da propaganda dos esforços de guerra (MORGAN, 1988, p. 11). Devido a sua característica de entrevista em um contexto de grupo, essa metodologia foi adaptada para a área de pesquisa em marketing, em que vem sendo utilizada na avaliação, por consumidores em potencial, de produtos a serem lançados no mercado. 
O Grupo Focal utiliza a interação do conjunto de pesquisados, como característica diferencial própria, para produzir dados e ideias que seriam menos acessíveis ao pesquisador num contexto de entrevista individual. De acordo com Bellenger et al. (1976), esse procedimento de ouvir-refletir-questionar/concordar-responder leva a respostas mais espontâneas dos participantes e a um alto nível de envolvimento no debate.

Merton et al. (1956) levantam quatro critérios para uma boa utilização da metodologia de grupo focal: cobrir o maior número possível de tópicos relevantes; proporcionar dados os mais específicos possíveis; promover uma interação que explore, em profundidade, os sentimentos dos participantes com relação ao tema abordado; e levar em conta o contexto pessoal de cada resposta. Os grupos são formados por quatro a 12 pessoas e a duração de cada sessão fica em torno de 1h30. Apenas duas questões relativas ao tema de investigação devem ser abordadas em cada sessão, que começa com uma breve introdução do moderador antes que a primeira questão seja posta em discussão. Nessa introdução, cabe-lhe situar o grupo dentro de seus objetivos como pesquisador: aprender com as experiências de cada componente do grupo e com as análises do tema pelo grupo; observar as regras do debate (falar um de cada vez; não manter conversas paralelas; incentivar a participação de todos); e solicitar que cada componente faça uma breve apresentação de si mesmo.

\section{Os ajustes do Grupo Focal para esta pesquisa}

Morgan (1988) recomenda que, antes que se inicie uma coleta de dados propriamente dita, sejam realizados um ou dois grupos focais experimentais que sirvam de base para o pesquisador. Esse teste pode mostrar se determinado tema irá "funcionar" num grupo focal, gerando a participação dos entrevistados através de debates e colocações sobre o assunto. Portanto, para testar a eficiência do método com relação ao objetivo da nossa pesquisa, foram organizados dois grupos experimentais, que abordaram questões relativas à EA no ensino formal, dentro da metodologia de Grupo Focal.

A análise das discussões nesses grupos mostrou que a metodologia realmente fornecia subsídios para uma discussão frutífera de 
temas relativos à educação ambiental formal, além de possibilitar boa permuta de experiências entre os membros de cada grupo. Assim como assinalaram Morgan e Spanish em sua pesquisa sobre a percepção de fatores de risco para ataques cardíacos (MORGAN, 1986; MORGAN; SPANISH, 1984; 1985), as sessões dos grupos começam com relativa incerteza dos participantes sobre o quanto os pares presentes compartilham de um conjunto de perspectivas sobre o tema a ser discutido. Mas, à medida que os membros do grupo apresentam suas experiências e perspectivas sobre o tema, eles próprios acabam encontrando meios de expressar sua concordância ou discordância com o que está sendo abordado. A partir dessa constatação, buscou-se preparar material para inserir a metodologia de grupo focal em oficinas destinadas ao objetivo de reunir voluntários para a presente pesquisa.

\section{0 desenho final}

Para reunir voluntários para esta pesquisa, anunciamos a oferta da oficina Formação de Líderes de Grupos de Discussão em Educação Ambiental. Ao fazê-lo, deixamos claro o propósito de nossa pesquisa. $\mathrm{O}$ programa da oficina foi construído com a finalidade de demonstrar o potencial da metodologia de Grupo Focal para o desenvolvimento profissional e a construção de uma identidade docente em grupos de discussão que os participantes da oficina viessem a liderar.

Com esses objetivos, foi preparada a oficina, que se compunha, primeiramente, de um Grupo Focal sobre Educação Ambiental Formal. Para iniciar o debate, selecionamos temas de projetos em EA apresentados no Relatório do Levantamento Nacional de Projetos de Educação Ambiental do Ministério do Meio Ambiente (BRASIL, 1997a, p. 16). Com base nessa estratégia, desejávamos, num primeiro momento, obter um panorama das ideias dos professores inscritos na oficina, no que se relacionava aos temas que eles consideravam relevantes na geração de ações voltadas para a educação ambiental.

A primeira etapa da oficina pode ser acompanhada com o auxílio da FIG.1. Para facilitar a discussão, optou-se por dividir o grupo de participantes em grupos menores (subgrupos), de dois a quatro componentes, dependendo do número total dos presentes a cada edição 
da oficina. Vinte e oito temas foram selecionados para serem apresentados a eles (QUADRO 1). Dessa forma, cada subgrupo recebeu 28 filipetas com os temas selecionados. Solicitamos aos subgrupos que escolhessem, primeiramente, os cinco mais importantes a serem tratados pelo campo da educação ambiental. Os resultados da primeira etapa eram discutidos, sob o comando do moderador, até que se chegasse, de comum acordo a todos os participantes, a cinco temas. O objetivo dessa primeira etapa era conseguir cinco temas gerais que pudessem servir de base à escolha dos temas de uma segunda etapa, quando os subgrupos deveriam escolher os cinco temas mais importantes a serem tratados na educação ambiental formal. Após a escolha dos temas da segunda etapa, dava-se início ao Grupo Focal, cujos participantes iriam explicar o porquê da escolha de determinados temas para a Educação Ambiental na escola, de preferência ilustrando essa escolha com experiências próprias, objetivo primordial da nossa coleta de dados.

Após o debate, a segunda parte da oficina se dedicava justamente à explicitação do que é um Grupo Focal, como ele deve ser conduzido e de que maneira os professores podem tirar proveito dessa metodologia em sua relação profissional com os pares. Uma apostila com as principais diretrizes era então distribuída, e dúvidas e opiniões dos participantes eram colocadas e discutidas pelo grupo, juntamente com a participação do moderador e coordenador da oficina.

No total, foram realizadas seis oficinas. Como se encaixaram melhor nas recomendações da condução dos grupos, cinco delas foram escolhidas na análise de dados, resultando num total de 59 participantes. Entre estes, 43 estavam diretamente envolvidos com a profissão docente. 
FIGURA 1 - Descrição passo a passo da primeira etapa da Oficina Formação de Líderes de Grupos de Discussão em Educação Ambiental, em que os participantes deveriam escolher os cinco temas mais importantes a serem tratados pelo campo da Educação Ambiental.

\section{PARTE I}

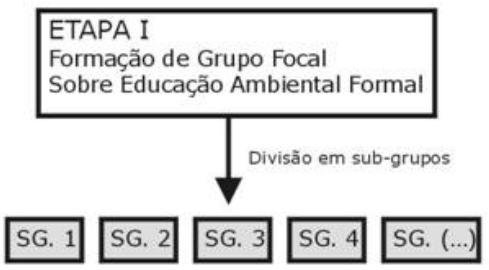

Cada Grupo recebe 28 temas, dos quais tem que selecionar 5

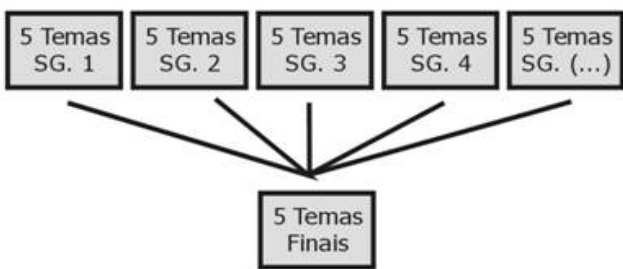

Dos Temas escolhidos nos sub-grupos, são escolhidos 5 Temas Finais

Dos 43 professores pesquisados, 35 eram do sexo feminino $(81 \%)$ e 8 do sexo masculino (19\%); 24 professores $(56 \%)$ participaram da oficina no estado de Minas Gerais, enquanto 19 professores (44\%) participaram no estado do Rio de Janeiro. A maioria dos professores que informou sobre sua área de formação vem da Biologia (14 professores cerca de 33\% do total). Analogamente, a maioria dos professores que informou sua área de atuação leciona Ciências (6 professores - 14\%), Língua Portuguesa (4 professores - 9\%), Geografia e Matemática (ambos com 7\% - 3 professores cada); 08 (19\%) dos 43 professores pesquisados dão aula no primeiro segmento do ensino fundamental, ao passo que 17 professores (40\%) atuam no segundo segmento e 8 (19\%) são professores do ensino médio regular. 
QUADRO 1 - Temas classificados no Relatório do Levantamento Nacional de Projetos de EA do MMA e utilizados na Oficina Formação de Líderes de Grupos de Discussão em EA

\section{Temas Escolhidos}

1. Problemas de realidade local e geral.

2. Lixo/ reciclagem.

3- Ambiente urbano.

4- Ações comunitárias.

5- Ecossistemas locais.

6. Áreas de preservação ambiental.

7. Bacias hidrográficas, mananciais.

8. Flora e fauna da região.

9. Bairro/ município/ comunidade.

10. Unidades de conservação.

11- Poluição e/ou tratamento de água.

12. Saúde/ doença.

13- Saneamento básico.

\section{Analisando as falas dos professores}

As transcrições dos grupos focais realizados durante as oficinas renderam grande quantidade de material bruto, que teve de ser lido, contextualizado e separado em partes relevantes e não-relevantes para a pesquisa. Então, num primeiro momento, extraímos, de cada transcrição de grupo focal as partes da narrativa que abordavam o tema proposto: Educação Ambiental na Escola. Para esse primeiro recorte dos dados, utilizamos um programa de análise qualitativa, o Hyper Research versão 2.0 (RESEARCHWARE, 1999).

Observamos que os trechos escolhidos para análise alternavam o relato de experiência com considerações pessoais sobre a experiência relatada. Chamamos esses trechos de "episódios". Com base nos 17 episódios narrados, classificamos as experiências e as perspectivas dos professores pesquisados em categorias gerais, que têm nos mostrado de que modo eles comunicam aos pares seus saberes sobre a prática escolar da Educação Ambiental. 


\section{Exemplo de categorização: professor Gérson}

Para exemplificar como foi feita a categorização dos episódios, vamos transcrever aqui um desses episódios, que foi narrado por um professor que participou de uma das oficinas de EA. Seu pseudônimo é Gérson. O professor Gérson leciona Biologia em turmas do ensino médio curso de formação de professores, de um colégio particular do Rio de Janeiro. Aqui ele nos relata um trabalho que realizou com uma de suas turmas:

Gérson - No terceiro ano, nós fizemos um trabalho que foi a identificação do meio ambiente nos meios de cultura. Então eles tiveram que procurar (...) cinco músicas que falassem do meio ambiente de alguma maneira e fazer uma análise crítica dessas músicas (...); pegar cinco histórias (...) e passar a imagem de meio ambiente que estava nessas historinhas (...); tiveram também que procurar cinco obras de arte que, de alguma maneira, o meio ambiente fosse [retratado] ali e tentar passar aí a visão de cada um sobre como ele via o meio ambiente naquelas obras de arte.

Notamos que ele, ao propor esse trabalho, escolhe propositadamente não indicar o material a ser analisado, incentivando, dessa forma, a iniciativa dos alunos em pesquisar material escolhido por eles próprios e, mais importante de tudo, analisado por eles mesmos. Veremos, a seguir, que essa escolha teve um objetivo, ou seja, o que ele pretende com isso está intimamente ligado ao modo como o professor procede:

Gérson - Quando você vê as historinhas que passam a floresta como sendo um local escuro onde mora a bruxa, onde mora o lobo mau, isso passa pra criança o quê? Uma idéia de que você tem que ter medo, pânico da floresta. A história dos três porquinhos: o lobo mau come os três porquinhos. Ah, o lobo mau então é o vilão da história? Ele é malvado? Não, há uma cadeia alimentar onde se o lobo mau não comer os porquinhos quem vai morrer é o lobo mau.

Ao ser questionado sobre o objetivo do trabalho, Gérson indica o que ele pretende com aquilo. No caso, vinculando conhecimentos biológicos (cadeia alimentar) às ideias dos alunos sobre meio ambiente, $\mathrm{o}$ professor estará instrumentalizando seu aluno para lecionar nas séries iniciais do ensino fundamental.

Note-se que podemos observar, ao longo do episódio narrado pelo professor Gérson, outra forma como ele procede para atingir seu 
objetivo. Ao deixar que os alunos exponham suas opiniões e façam suas próprias análises das músicas, livros e obras de arte que transmitem impressões sobre o meio ambiente, ele consegue diagnosticar os valores dos alunos com relação ao meio ambiente e utilizar-se desse diagnóstico na instrumentalização dos seus alunos:

Gérson - Quem é herói e quem é bandido nas historinhas em relação ao meio ambiente? Não tem, é uma questão de referencial que você pegue. Então pra que elas não usem a historinha que é normalmente contada como incentivo de uma aula de Português, de interpretação ou o que for, mas que elas não usem de maneira indevida...

A experiência com a prática docente mostrou ao professor Gérson que tornar o ambiente tema de trabalhos que contam com a participação ativa do aluno é uma boa maneira de inserir a Educação Ambiental no cotidiano da escola. A partir desses trabalhos, o professor pode utilizar-se de estratégias pedagógicas para informar o aluno não só dos conhecimentos específicos da disciplina, mas também dos conhecimentos do professor sobre ações voltadas para uma educação ambiental.

\section{Conclusões}

Pela leitura, pela contextualização e pela análise dos episódios narrados pelos professores, eles foram sendo classificados por nós, resultando nas categorias que apresentamos no QUADRO 2.

Observamos que os docentes possuem um saber sobre ações ambientalmente responsáveis e sobre seus objetivos que lembram em muito aqueles recomendados pelos especialistas em EA. Assim, o professor que se interessa pela área demonstra possuir os fundamentos para introduzir a Educação Ambiental no espaço escolar. A complexidade da atividade docente encontra consonância na complexidade da área ambiental, especificamente no campo da Educação Ambiental. Nesse contexto, as experiências profissionais do professor, ao longo da sua atividade docente, capacitam-no a aproximar-se da questão ambiental e a envolver-se com ela de maneira mais completa e eficiente do que com outras áreas que não convivem com questões tão complexas e dilemáticas. 
A velocidade das transformações econômicas, sociais e culturais atuais vem forçando os professores a se adaptarem rapidamente a problemas antes inéditos, que representam desafios, como os problemas ambientais: "Essa evolução da sociedade, cada vez mais rápida e de aparência às vezes caótica, repercute-se diretamente no ensino, transformando tanto as condições de acesso à profissão quanto seu exercício, assim como os percursos de carreira dos seus membros e sua identidade profissional" (TARDIF; LESSARD, 2008, p. 8).

Os professores geram, assim, um novo tipo de conhecimento a ser aplicado na escola: o conhecimento pedagógico da Educação Ambiental, que alia o conhecimento disciplinar, o conhecimento pedagógico, as experiências e a perspectiva profissional e pessoal do professor à realização de atividades de EA na escola, através da valorização dos saberes docentes e da sua importância no estabelecimento de processos de ensino-aprendizagem. Acreditamos que a tomada de consciência, pelo professor, da importância desse seu papel como implementador da EA formal pode não só potencializar o estabelecimento dessas práticas, como também colaborar com o estabelecimento de uma identidade profissional docente. Pelo estudo e sistematização dessas ações, contribui-se, finalmente, para a formação de um repertório de conbecimentos sobre a EA Formal.

QUADRO 2: Análise dos episódios narrados. Categorias de análise.

\section{PERSPECTIVAS DO PROFESSOR (O que pretende?)}

I. "Mobilizar" 0 aluno (discutindo e trabalhando questões ambientais).

II. "Instrumentalizar" 0 aluno (vinculando conhecimentos técnico-científicos às idéias sobre meio ambiente).

III. Fazer 0 aluno "vivenciar" determinados problemas ambientais.

IV. "Sensibilizar" 0 aluno para as questões ambientais.

\section{EXPERIÊNCIAS DO PROFESSOR (Como procede?)}

1. Diagnosticando valores dos alunos com relação a questões ambientais.

2. Abordando temas do universo local do aluno.

3. Abordando assuntos do dia-a-dia (e que geram discussão na sociedade).

4. Levantando idéias e concepções dos alunos sobre temas ambientais.

5. Incentivando as iniciativas dos alunos.

6. Transformando a escola numa microesfera de práticas socioambientais.

7. Abordando assuntos do universo cultural dos alunos. 


\section{Referências}

BELLENGER, Danny N., BERNHARDT, Kenneth L., GOLDSTUCKER, Jac. L. Qualitative Research in Marketing. Chicago: American Marketing Association, 1976. p. 7-28: Qualitative Research Techniques: focus group interviews.

BRASIL. Ministério do Meio Ambiente, dos Recursos Hídricos e da Amazônia Legal. Ministério da Educação e do Desporto. Levantamento Nacional de Projetos de Educação Ambiental-MMA. Brasília: I Conferência Nacional de Educação Ambiental, 1997a. (Relatório).

BRASIL. Secretaria de Educação Fundamental. Parâmetros Curriculares Nacionais: meio ambiente, saúde. Brasília, 1997b.

BRASIL. Constituição da República Federativa do Brasil. 1988.

BRUNER, Jerome. A cultura da educação. Porto Alegre: Artmed, 2001.

BRUNER, Jerome. Atos de significação. Porto Alegre: Artes Médicas, 1997.

CONNELLY, Michael F., CLANDININ, Jean D. Relatos de Experiencia e Investigación Narrativa. In: LARROSA, Jorge. Déjame que te cuente: ensayos sobre narrativa y educación. Barcelona: Laertes, 1995.

GAUTHIER, C. et al. Por uma teoria da pedagogia: pesquisas contemporâneas sobre o saber docente. Ijuí: Ed. UNIJUÍ, 1998. (Coleção fronteiras da educação).

GIMENO, J. El Curriculum: una reflexión sobre la práctica. Madrid: Morata, 1988 In:

PACHECO, José A. O pensamento e a aç̧ão do professor. Porto: Porto Editora, 1995.

MERTON, Robert K., FISKE, Marjorie, KENDALL, Patricia L. The focused interview. Glencoe: Free Press, 1956.

MORGAN, David L. Focus groups as qualitative research. London: Sage, 1988. (Qualitative research methods, 16).

MORGAN, David L. Personal relationships as an interface between social networks and social cognitions. Journal of Social and Personal Relationships, [s.l.], n. 3, p. 403-422, 1986.

MORGAN, David L., SPANISH, Margaret T. Social interaction and the cognitive organisation of health-relevant behaviour. Sociology of Health and Illness, [s.1.], n. 7, p. 401-422, 1985.

MORGAN, David L., SPANISH, Margaret T. Focus groups: a new tool for qualitative research. Qualitative Sociology, [s.l.], n. 7, p. 253-270, 1984.

NÓVOA, António (Org.). Vidas de professores. Porto: Porto Editora, 1992.

PACHECO, José A. O pensamento e a ação do professor. Porto: Porto Editora, 1995.

RESEARCHWARE, Inc. Hyper Research [Windows Version]. Version 2.0. California/London: Sage Publications Software, 1994-1999.

RICOEUR, Paul. The Narrative Function. In: THOMPSON, John B. (Ed.). Hermeneutics and the Human Sciences. Cambridge: Cambridge University Press, 1981 apud BRUNER, Jerome. Atos de significação. Porto Alegre: Artes Médicas, 1997a.

SCHÖN, Donald A. The reflective practitioner. New York: Basic Books, 1983.

SHULMAN, Lee S. Knowledge and Teaching: foundations of the New Reform. Harvard Educational Review, v. 57, n. 1, p. 1-22, feb. 1987.

SHULMAN, Lee S. Those Who Understand: knowledge growth in teaching. Educational Researcher, [s.l.], v. 15, n. 2, p. 4-14, feb. 1986.

TARDIF, Maurice. Saberes docentes e formação profissional. 9 ed. Petrópolis, RJ: Vozes, 2008. TARDIF, Maurice, LESSARD, Claude. O oficio de professor: história, perspectivas e 
desafios internacionais. Petrópolis, RJ: Vozes, 2008.

VAZ, Arnaldo, MENDES, Regina, MAUÉS, Ely. Episódios e narrativas de professores: experiências e perspectivas docentes discutidas a partir de pesquisa sobre conhecimento pedagógico de conteúdo. In: REUNIÃO ANUAL DA ANPED, 24, 2001, Caxambu. Anais... Rio de Janeiro, 2001. p. 1-12.

\section{Nota}

${ }^{1}$ Financiamento: CAPES

Recebido: 30/03/09

Aprovado: 21/09/09

Contato:

Universidade Federal de Minas Gerais

Escola de II Grau

Colégio Técnico

Av. Antonio Carlos, 6627 - Coltec - sala 255

Pampulha

Belo Horizonte - MG

CEP 31270-901 